\title{
EXPLORE
}

\section{Analisis Tata Kelola Sistem Informasi Balai Penelitian Lingkungan Pertanian Menggunakan Framework Cobit-5}

\author{
Bambang Satrio, Likco Desvian Herindra, Aris Puji Widodo \\ Sistem Informasi, Sekolah Pascasarjana \\ Universitas Diponegoro \\ Semarang, Indonesia \\ bambang.satrio04@gmail.com, likcobalingtan@gmail.com, arispw@gmail.com
}

\begin{abstract}
Agricultural Environmental Research Center - Ministry of Agriculture in the process of public information is assisted by information technology (IT) in managing various divisions which include, dissemination services, laboratories, technical services and research services. To find out whether the public information system is working as planned, a managerial analysis of information system technology is needed. The research conducted has the aim of knowing the maturity level and designing improvements by monitoring, reinventing and measuring the application of information technology. In this study, the research flow method was carried out by studying literature (review of IT application and literature study), COBIT domain, data input, data analysis management, and conclusion of IT governance planning. IT governance analysis is carried out using the COBIT 5 framework with 4 domains, namely APO, BAI, DSS, and MEA. The method of data collection in this study was by answering in interviews and filling out questionnaires, then analysis could be carried out to determine levels and preferences. The maturity level obtained from the analysis shows that the maturity level of the Balingtan public information system is currently at level 3 (defined process) so that the Balingtan public information system has been standardized, documented, and communicated properly.
\end{abstract}

Keywords: IT governance analysis, COBIT 5, Information Systems, Indonesian Agricultural Environment Research Institute, Maturity Level.

\begin{abstract}
Abstrak-Balai Penelitian Lingkungan Pertanian - Kementerian Pertanian dalam proses informasi publiknya dibantu oleh teknologi informasi (TI) dalam mengelola berbagai divisi yang di antaranya adalah, pelayanan diseminasi, laboratorium, pelayanan teknis dan jasa penelitian. Agar mengetahui apakah sistem informasi publik sudah bekerja sesuai dengan yang direncanakan, maka diperlukan analisis manajerial teknologi sistem informasi. Penelitian yang dilakukan memiliki tujuan agar tahu kadar kematangan (maturity leve) dan perancangan perbaikan dengan monitoring, peninjauan kembali dan pengukuran dalam penerapan teknologi informasi. Pada penelitian ini, metode alur penelitian yang dilakukan dengan studi literatur (telaah penerapan TI dan studi pustaka), penentuan domain COBIT, penginputan data, analisis pengelolaan data, dan kesimpulan perencanaan tata kelola TI. Analisis tata kelola TI dilakukan menggunakan framework COBIT 5 dengan 4 domain, yaitu APO, BAI, DSS, dan MEA. Metode pengumpulan data pada penelitian ini dengan cara tanya jawab dalam wawancara dan pengisian kuesioner, selanjutnya dilaksanakan analisis agar mengetahui kadar kematangan dan kesenjangan. Tingkat kematangan yang didapatkan dari hasil analisis bahwa maturity level sistem informasi publik Balingtan saat ini pada tingkat level 3 (defined process), sehingga sistem informasi publik Balingtan sudah di standarisasi, didokumentasi, dan dikomunikasikan dengan baik.
\end{abstract}

Kata Kunci: Analisis tata kelola TI, COBIT 5, Sistem Informasi, Balai Penelitian Lingkungan Pertanian, Tingkat Kematangan.

\section{Pendahuluan}

Teknologi informasi (TI) pada sekarang ini merupakan sesuatu yang sangat penting bagi hampir semua organisasi, perusahaan maupun sebuah lembaga untuk membantu dalam meningkatkan efektivitas dan efisiensi proses kinerja. Pemanfaatan TI sekarang tidak hanya diterapkan di organisasi swasta, namun juga di organisasi/lembaga pemerintahan. Upaya penerapan TI pada lembaga pemerintahan berbasis elektronik ( $e$ - government) ini ditujukan untuk meningkatkan kualitas layanan publik menjadi lebih efektif, efisien, dan dapat mencakup berbagai kalangan masyarakat [1]. Penerapan TI di suatu lembaga memiliki risiko kegagalan yang cukup tinggi dengan biaya yang besar [2]. Namun, penerapan IT juga memberikan peluang dan kesempatan pada lembaga mengalami transformasi dan peningkatan produktivitas kinerja yang telah berjalan [3]. Guna mencapai tujuan 
tersebut dibutuhkan manajemen sistem teknologi informasi yang terstruktur dan berkualitas, agar keberadaan TI dirasakan manfaatnya sehingga dapat meraih tujuan Organisasi/ lembaga [1].

Information Systems Audit and Control Association (ISACA) mendefinisikan tahapan tata pelaksanaan teknologi informasi sebagai kumpulan proses organisasi untuk memastikan bahwa TI perusahaan bisa menopang, memperluas strategi serta tujuan lembaga [4]. Salah satu rangkaian pekerjaan (framework) standar yang dapat dipakai guna membantu cara pengendalian IT adalah COBIT (Control Objectives for Information and Related Technology) [5]. Penelitian yang dilakukan akan memakai COBIT 5 sebagai framework analisis. COBIT 5 menyajikan struktur pekerjaan yang menyeluruh yang mana memberikan bantuan bagi perusahaan untuk merengkuh tujuan mereka pada perencanaan dan manajemen TI perusahaan dan berkontribusi bagi perusahaan dalam membentuk nilai maksimum dari TI melalui keseimbangan yang terjaga antara mewujudkan keuntungan dan pengoptimalan kadar resiko dan pemakaian sumber daya [6].

Unit Pengurusan teknis pada pengembangan dan penelitian berada dalam kontrol pengamatan serta tanggung jawab Balai Penelitian Lingkungan Pertanian (Balingtan). Salah satu arah kebijakan dan strategi litbang pertanian adalah memotivasi dalam menciptakan teknologi terbaru di pertanian secara sistematis guna memenuhi kebutuhan pembangunan pertanian dengan rancangan penguatan padu pada kegiatan tahapan

\section{Metodologi}

\section{A. Framework COBIT 5}

Suatu teknik yang dilakukan dengan melakukan tahapan ilmiah yang dikerjakan oleh peneliti untuk mengumpulkan data dan informasi dengan tujuan untuk menjawab rumusan masalah yang di teliti. Kerangka kerja (Framework) yang digunakan untuk tata kelola TI (IT Governance) ada banyak sekali, salah satu IT Governance yang banyak diterapkan adalah COBIT (Control Objectives for Information and related Technology) [14].

COBIT (Control Objectives for Information and Related Technology) ialah instrumen panduan general (best practice) guna manajerial teknologi informasi, yang dirancang oleh Information System and Control Association (ISACA), dan IT Governance Institute (ITGI) pada tahun 1996 [15]. Pada bulan April 2012, ISACA menerbitkan COBIT 5, yang adalah struktur pekerjaan untuk IT Governance manajemen perusahaan TI. COBIT 5 menghubungkan COBIT 4.1, Val IT dan Risk IT menjadi kesatuan struktur pekerjaan yang berlaku sebagai struktur kerja perusahaan yang selaras dan bisa dikelola dengan TOGAF dan ITIL [16]. COBIT 5 merupakan framework baru, yang mengombinasikan tata laksana dan teknik pengelolaan perusahaan di mana mempunyai pedoman praktik, model dan alat analisis yang secara umum diperoleh guna berkontribusi dalam peningkatan performa tata kelola TI [17]. COBIT melimpahkan auditor, pengguna teknologi informasi, dan manajer, serangkaian tahapan, di mana secara general diterima, indicator sistem dan pengaplikasian penelitian, penelahan lebih spesifik, dan diseminasi dengan kegiatan penyuluhan pertanian [7]. Pada awal tahun 2020, pelaksanaan strategi Balingtan berupa kegiatan publik yang bertemu langsung (offline) sedikit terkendala karena terjadinya pandemi Coronavirus disease (COVID-19). Munculnya suatu keadaan yang memberikan tantangan pembangunan pertanian pada era kemajuan Information and Communication Technology (ICT), Balingtan dituntut untuk melakukan penyesuaian dalam pelaksanaan arah kebijakan dan strategi kegiatan offline, dengan memaksimalkan penerapan teknologi informasi pada sistem informasi publik Balingtan.

Balingtan harus dapat memaksimalkan tingkat kematangan (maturity level) penerapan teknologi informasi pada lembaga, agar tujuan arah kebijakan dan strategi Balingtan dapat tercapai. Untuk mengetahui keberhasilan dan tingkat kematangan dari penerapan teknologi informasi, maka perlu dilakukan monitoring dan evaluasi agar dapat diketahui tingkat kematangan penerapan TI menggunakan framework COBIT 5. Penelitian yang dilakukan mengenai tata kelola teknologi informasi pada perusahaan secara umum [8]-[10] dan pada suatu lembaga pemerintahan telah banyak dilakukan [1], [11]-[13], namun masih belum ada penelitian yang spesifik pada pelayanan di sistem informasi Balingtan. Penelitian ini akan fokus pada domain APO, BAI, DSS, dan MEA, dengan 9 proses (DSS01, DSS02, DSS04, DSS06, APO09, MEA01, MEA02, MEA03, dan BAI04) yang relevan dan sesuai untuk dijadikan masukan ke Balingtan sehingga kematangan penggunaan TI bisa terwujud.

yang baik guna berkontribusi dalam membantu mengoptimalkan manfaat yang didapat dengan pemakaian teknologi informasi dan pembaruan "yang selaras dengan apa yang perusahaan kendalikan" [18].

Pada COBIT 5, pemberian nilai terhadap kadar kematangan pengelolaan TI memakai maturity model. Dengan total level penilaian terpetakan menjadi 6 tingkatan level, penjabaran tingkat level kematangan dari Process maturity model [17] sebagai berikut :

1. Level 0 Non-Existent

Merupakan tahapan pertama dalam memanajemen teknologi Informasi.

2. Level 1 Initial/ad Hoc

Munculnya kesadaran pada perusahaan terkait persoalan yang harus diselesaikan, tetapi prosedur belum ada penyeragaman dalam pelaksanaan.

3. Level 2 Repeatable but Intuitive

Langkah pengembangan proses.

4. Level 3 Defined Process

System yang telah mendapat standarisasi, dokumentasi, dan mengkomunikasikan dengan training.

5. Level 4 Managed and Measurable

Manajemen melakukan pengontrolan dan pengukuran apakah semua sudah dikerjakan memenuhi prosedur, serta mengambil langkah solutif ketika proses tidak berjalan dengan efektif.

6. Level 5 Optimised.

Tahapan yang sudah tersesuaikan dengan best practice berlandaskan hasil pengembangan sehingga membuat 
perusahaan bisa dengan cepat untuk menyesuaikan lingkungan.
Penghitungan nilai tingkat kematangan domain yang berlandaskan pada COBIT Management Guidelines dapat dilihat di Tabel 1 berikut [16]

Tabel 1 Hasil Nilai Untuk Domain

\begin{tabular}{ll}
\hline Range Nilai & Nilai Maturity \\
\hline $0.0-0.49$ & Non-Existent \\
$0.50-1.49$ & Initial/Ad Hoc \\
$1.50-2.49$ & Repeatable but Intuitive \\
$2.50-3.49$ & Defined Process \\
$3.50-4.49$ & Managed dan Measurable \\
$4.50-5.00$ & Optimized \\
\hline
\end{tabular}

Selain itu, COBIT 5 juga mempunyai 5 Domain yang mencakup 37 tahapan TI di mana nantinya akan di analisa selaras dengan status keadaan lembaga. Berikut adalah penjelasan secara umum tentang 5 domain COBIT [17]:

1. Evaluate, Direct and Monitor (EDM), ialah domain proses yang berhubungan dengan evaluasi dan pengevaluasian, pemberian arahan dan supervisi. Wewenang EDM mempunyai 5 sub wewenang. Wewenang EDM ini bersumber dari area tata kelola informasi teknologi.

2. Align, Plan and Organize (APO), ialah wewenang proses yang berhubungan dengan penyesuaian, merencanakan dan manajerial teknologi informasi. Wewenang APO mempunyai 13 sub wewenang. Wewenang APO memiliki asal dari manajemen teknologi informasi.

3. Build, Acquire and Implement (BAI), ialah domain proses pengembangan dan pengaplikasian TI. Wewenang BAI mempunyai 10 sub wewenang. Wewenang BAI bersumber dari area manajemen teknologi informasi.

4. Deliver, Service and Support (DSS), ialah Wewenang proses yang berhubungan dengan pendistribusian dalam memberikan layanan dan bantuan TI kepada lembaga. Wewenang DSS mempunyai 6 sub wewenang. Wewenang yang bersumber dari area manajemen teknologi informasi.

5. Monitor, Evaluate and Assess (MEA), ialah domain tentang supervisi (pengawasan), penilaian kembali dan tahapan pencobaan TI di lembaga atau organisasi. Wewenang ini mempunyai 3 sub wewenang. Domain ini merupakan awal dari area manajemen teknologi informasi.

Selanjutnya, guna memahami domain tahapan apa yang di analisa selaras dengan status keadaan lembaga, dilakukan pembagian lebih awal terkait tujuan institusi dan tujuan terkait teknologi informasi yang terdapat pada lembaga pemerintahan. Pembagian ini dilaksanakan sesudah peneliti mengetahui tujuan bisnis lembaga dan selanjutnya dapat dipetakan dalam tujuan bisnis COBIT 5 [11].

\section{B. Kerangka Penelitian}

Teknik penelitian yang akan diterapkan peneliti pada penelitian sekarang adalah teknik kuantitatif, dengan memfokuskan pada aspek pengetahuan yang di permasalahkan, di mana pada penelitian ini melalui sebuah studi kasus, adalah suatu tata kelola yang terstruktur dalam memahami suatu peristiwa, mendapatkan data, menganalisa data dan membuat laporan hasil [19]. Berikut alur penelitian tata kelola teknologi informasi yang akan dilakukan selama penelitian ini, dapat dilihat pada Gambar 1 [16], [20].

1. Studi literatur, melakukan penelitian di lapangan terkait penerapan teknologi informasi dan mendapatkan informasi pendukung meliputi Visi dan Misi Balingtan, serta mengumpulkan data dari berbagai sumber pustaka baik buku, internet, maupun penelitian terdahulu yang terkait.

2. Pemilihan domain COBIT, dengan cara mempelajari rencana strategis Balingtan untuk mengetahui visi, misi, arah kebijakan dan strategi. Hal ini bertujuan agar proses tata kelola TI sesuai dan selaras dengan tujuan lembaga.

3. Pengumpulan data, dengan penyusunan kuesioner dalam cakupan domain APO, BAI, DSS, dan MEA. Kemudian wawancara pada pihak pelaksana sistem informasi publik Balingtan.

4. Analisis data, dari hasil kuesioner dan wawancara dapat diketahui tingkat kematangan pelaksanaan dengan keadaan saat ini dan keadaan yang diharapkan.

5. Analisis kesenjangan (GAP), untuk dapat mengetahui perbandingan keadaan tingkat kesigapan penerapan proses TI saat ini dengan kondisi tingkat kematangan proses TI yang selaras dengan keinginan lembaga.

6. Perencanaan Tata pelaksana Teknologi Informasi, Membuat usulan terhadap analisa tingkat kematangan. 


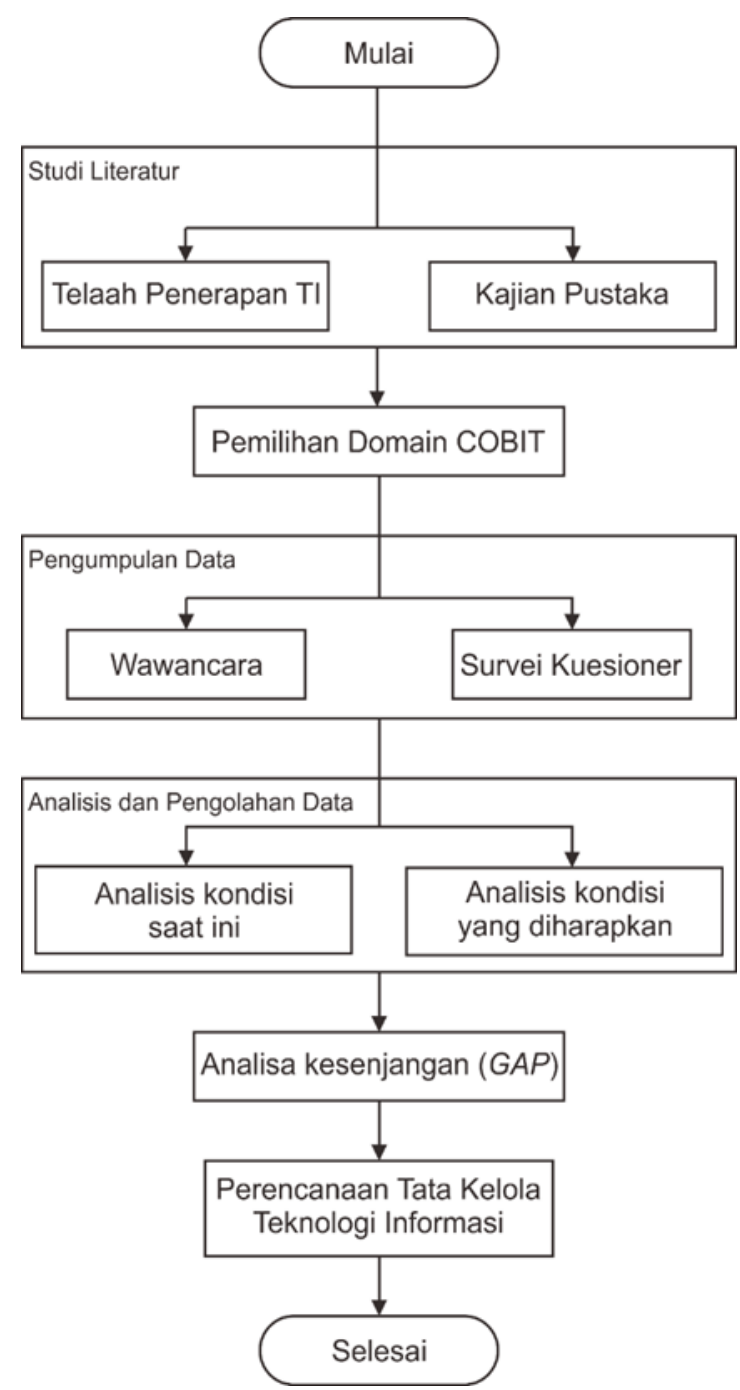

Gambar 1. Alur Penelitian

\section{Metode Pengumpulan Data}

\section{Wawancara}

Wawancara dilakukan dengan mengajukan pertanyaanpertanyaan pada responden dalam organisasi dan pihak pelaksana terkait pemanfaatan teknologi informasi pada Sistem Informasi Balingtan, guna mendapatkan data dan informasi yang diinginkan dalam penelitian [10].

\section{Kuesioner}

Metode ini dilakukan dengan cara membuat kuesioner online lalu di sebarkan pada staff dan pengguna terkait dalam pemanfaatan teknologi informasi pada Sistem Informasi Balingtan. Jumlah responden yang mengisi kuesioner berjumlah 927 orang [9]

\section{Metode Analisis}

Berdasarkan pengolahan data dengan metode kuesioner dan wawancara dilakukan analisis berikut:

1. Analisis Tingkat Kematangan (Maturity Model)

Analisis ini berdasarkan hasil kuesioner tata kelola TI terkait proses pemanfaatan teknologi informasi pada Sistem Informasi Balingtan pada governance practice kerangka kerja COBIT 5 domain APO, BAI, DSS, dan MEA terhadap 927 responden.

2. Analisis Kesenjangan (Gap Analysis)

Analisis kesenjangan dipakai guna mendapatkan selisih tingkat kematangan yang telah di tuju dan dicapai atau diinginkan, dengan menggunakan rumus (1)(2) [8]. Di mana hasil analisis ini bisa dipakai menjadi instrumen perbaikan dalam pencapaian tata laksana TI yang lebih baik.

$$
\begin{aligned}
& \text { indek kematangan atribut }=\frac{\sum(\text { Total Jawaban } x \text { Bobot }}{\text { Jumlah Responden }} \\
& \text { Indeks kematangan }=\frac{\sum \text { Indeks Kematangan Atribut }}{\sum \text { Aktivitas }}
\end{aligned}
$$




\section{Hasil dan Pembahasan}

Beberapa layanan dan informasi publik pada sistem informasi Balai Penelitian Lingkungan Pertanian yang dapat diketahui dari hasil telaah penerapan TI pada sistem informasi Balingtan:

1. Laboratorium Balingtan, yang terdiri dari Laboratorium Gas Rumah Kaca (Lab. GRK)

2. Laboratorium Terpadu

3. Publikasi Balingtan, hasil penelitian yang diperoleh Balai Penelitian Lingkungan Pertanian Pati Jawa Tengah berupa Prosiding, leaflet dan lain-lain.

4. Layanan Jasa Balingtan, akses sarana laboratorium, perpustakaan, kebun percobaan, embung, stasiun klimatologi, dll.

5. Informasi Publik Balai Penelitian Lingkungan Pertanian, berbagai informasi yang dapat publik akses seperti Laporan Daftar Isian Pelaksanaan Anggaran
(DIPA), Akses informasi publikasi penelitian, Laporan Kinerja (LAKIN), Laporan Keuangan, Laporan Tahunan, Pagu Anggaran, Rencana Kinerja Tahunan (RKT), Aset, Catatan Atas Laporan Keuangan (CALK), Realisasi Anggaran, Peraturan Pemerintahan, Surat Perjanjian dengan Pihak Ketiga, Laporan Harta Kekayaan Penyelenggara Negara (LHKPN), Rencana Strategi (RENSTRA), dan lainlain.

A. Enterprise goals

Tahapan pertama yang dilaksanakan pada langkah ini ialah dengan menganalisis COBIT Enterprise Goals yang cocok dan searah dengan goal Balai Penelitian Lingkungan Pertanian. Dari visi dan misi lembaga maka didapatkan enterprise goals yang paling sesuai, dapat dilihat pada Tabel 2 [21]:

Tabel 2 Enterprise Goals Balingtan

\begin{tabular}{ll}
\hline Visi & $\begin{array}{l}\text { Menjadi Lembaga Penelitian Lingkungan Pertanian Terkemuka dalam Mewujudkan Sistem } \\
\text { Pertanian Bioindustri Berkelanjutan }\end{array}$ \\
\hline Misi & 1. $\begin{array}{l}\text { Melakukan penelitian teknologi penanggulangan dan pencegahan kerusakan lingkungan } \\
\text { dan pencemaran gas dari rumah kaca di lahan pertanian }\end{array}$ \\
& $\begin{array}{l}\text { 2. } \\
\text { Mendayagunakan dan mendiseminasikan hasil-hasil penelitian lingkungan pertanian serta } \\
\text { membangun kerja sama dalam penambahan khazanah IT pada suasana pertanian dengan } \\
\text { lembaga yang ada di negeri dan diluar negeri }\end{array}$ \\
Enterprise Goals & $\begin{array}{l}\text { 3. Pengembangan relasi dalam bekerjasama baik dalam negeri maupun luar negeri } \\
\text { Business service continuity and availability }\end{array}$ \\
\hline
\end{tabular}

B. Mapping Enterprise Goal to It-Related Goals

Pada tahap sebelumnya telah didapatkan enterprise goals yaitu Business service continuity and availability, seperti yang terlihat pada Tabel 3. Enterprise Goals ini kemudian dipetakan pada IT Goals COBIT.

Tabel 3 Tujuan Balingtan

\begin{tabular}{ll}
\hline Enterprise Goals & Business service continuity and availability \\
\hline & Managed IT-related business risk \\
& Security of information, processing \\
Mapping Enterprise Goals to IT-related Goals & infrastructure and applications \\
& Availability of reliable and useful \\
& information for decision making \\
\hline
\end{tabular}

\section{Mapping It-Related Goals to It-Related Processes}

Mapping IT-related Goals to Processes adalah proses memetakan tujuan teknologi informasi ke dalam proses COBIT 5, yang dapat di lihat prosesnya pada [6].

Pada tahapan ini didapatkan COBIT Process yang terkait yaitu EDM03, APO09, APO10, APO12, APO13, BAI01,
BAI04, BAI6, BAI10, DSS01, DSS02, DSS03, DSS04, DSS05, DSS06, MEA01, MEA02, dan MEA03. Namun, penelitian ini dibatasi dengan memilih domain DSS01, DSS02, DSS04, DSS06, APO09, MEA01, MEA02, MEA03, BAI04 yang sesuai dengan tujuan penelitian, bisa dilihat di Tabel 4.

Tabel 4 Pemilihan Domain COBIT Balingtan

\begin{tabular}{lll}
\hline IT-related Goals & $\begin{array}{l}\text { Mapping Enterprise Goals to IT- } \\
\text { related Goals }\end{array}$ \\
\hline $\begin{array}{l}\text { Managed IT-related business risk } \\
\begin{array}{l}\text { Security of information, processing infrastructure and } \\
\text { applications }\end{array}\end{array}$ & $\begin{array}{l}\text { DSS01, DSS02, DSS04, DSS06, } \\
\text { MEA01, MEA02, MEA03 }\end{array}$ \\
\end{tabular}




\section{Pengolahan Data Dan Perhitungan Maturity} Level

Berlandaskan penentuan tahapan COBIT yang sudah dijabarkan, ada 9 tahapan COBIT yang akan dilakukan pengukuran pada kadar kematangannya. Tahapan evaluasi, setiap domain dinilai melalui tahapan proses berawal dari level 1 hingga level 5. Keputusan peringkat guna setiap level ada 4, yaitu null $(\mathrm{N})$, partially $(\mathrm{P})$, largely achieved (L) dan fully achieved (f) [22]. Suatu tahapan dikatakan sudah mendapat suatu level jika rating berada pada tingkatan L atau F. Akan tetapi, apabila suatu proses bisa meneruskan penilaian ke level selanjutnya apabila rating pada suatu level telah meraih rating $\mathrm{F}$. Dari hasil analisis dan pengumpulan data dengan telaah penerapan TI COBIT 5, dokumen, dan wawancara dapat diketahui bahwa kondisi yang diharapkan pada penerapan sistem informasi Balingtan domain APO, BAI, DSS, dan MEA ada di level 4 (managed and measurable).

Kemudian, berikut perhitungan nilai kematangan tiap domain:

APO09 $\mathrm{NK}=(0 \mathrm{x} 0)+(5 \times 1)+(30 \mathrm{x} 2)+(334 \mathrm{x} 3)+$ $(558 \times 4)+(0 \times 5) / 927=3,55$

$\mathrm{BAI} 04 \mathrm{NK}=(0 \mathrm{x} 0)+(0 \mathrm{x} 1)+(73 \mathrm{x} 2)+(654 \mathrm{x} 3)+(200 \mathrm{x} 4)$ $+(0 \times 5) / 927=3,13$

DSS01 NK $=(0 \mathrm{x} 0)+(0 \mathrm{x} 1)+(10 \mathrm{x} 2)+(692 \mathrm{x} 3)+(225 \mathrm{x} 4)$ $+(0 \times 5) / 927=3,23$

DSS02 NK $=(0 \mathrm{x} 0)+(2 \mathrm{x} 1)+(4 \mathrm{x} 2)+(681 \mathrm{x} 3)+(240 \mathrm{x} 4)$ $+(0 \times 5) / 927=3,25$

DSS04 NK $=(0 \mathrm{x} 0)+(13 \mathrm{x} 1)+(5 \mathrm{x} 2)+(166 \mathrm{x} 3)+(743 \mathrm{x} 4)$ $+(0 \times 5) / 927=3,76$

DSS06 NK $=(0 \mathrm{x} 0)+(7 \mathrm{x} 1)+(22 \mathrm{x} 2)+(774 \mathrm{x} 3)+(124 \mathrm{x} 4)$ $+(0 \times 5) / 927=3,09$
MEA01 $\mathrm{NK}=(0 \mathrm{x} 0)+(1 \mathrm{x} 1)+(12 \mathrm{x} 2)+(717 \mathrm{x} 3)+$ $(197 \times 4)+(0 \times 5) / 927=3,19$

MEA02 NK $=(0 \mathrm{x} 0)+(2 \mathrm{x} 1)+(7 \mathrm{x} 2)+(589 \mathrm{x} 3)+(329 \mathrm{x} 4)$ $+(0 \times 5) / 927=3,34$

MEA03 NK $=(0 x 0)+(2 \times 1)+(1 \times 2)+(601 \times 3)+(323 \times 4)$ $+(0 \times 5) / 927=3,34$

Nilai mean pada proses DSS01, DSS02, DSS04, DSS06, APO09, MEA01, MEA02, MEA03, dan BAI04 adalah 3,32. Sistem informasi publik Balingtan sudah di standarisasi, didokumentasi, dan dikomunikasikan melalui pelatihan serta sudah melalui tahapan Defined Process dalam tata kelola teknologi informasinya.

\section{E. Analisis GAP}

Pada kegiatan bisnis, analisis gap dipakai untuk penentuan tahapan yang diambil untuk beralih dari keadaan saat ini menuju keadaan yang diinginkan atau status keadaan yang akan datang dan dijadikan tujuan [23]. Kondisi sistem informasi yang ada di Balai Penelitian Lingkungan Pertanian dapat dilihat berdasarkan hasil perhitungan maturity level, pada Tabel 5 dan secara spesifik bisa dicermati pada grafik Gambar 2. Pada level 3 bermakna lembaga telah melakukan penilaian tahapan bisnis yang telah di tata pelaksanaannya, diaplikasikan dan diterjemahkan dengan terstruktur serta menjalankan capaian hasil dari visi diterapkan di institusi tersebut. Pada level 4 tahapan ditanya bagaimana lembaga melaksanakan tahapan TI dalam batasan yang sudah pasti, serta pada level 5 bagaimana institusi bisa melaksanakan inovasi dalam perbaikan teknologi informasi yang berkelanjutan sehingga proses bisnis dapat berjalan dengan stabil dan konstan ke depannya di Balai Penelitian Lingkungan Pertanian [24].

Tabel 5 Tingkat Kematangan

\begin{tabular}{cccc}
\hline Proses & Current Maturity Level & $\begin{array}{c}\text { Expect Maturity } \\
\text { Level }\end{array}$ & GAP \\
\hline APO09 & 3,55 & 4 & 0,45 \\
BAI04 & 3,13 & 4 & 0,87 \\
DSS01 & 3,23 & 4 & 0,77 \\
DSS02 & 3,25 & 4 & 0,75 \\
DSS04 & 3,76 & 4 & 0,24 \\
DSS06 & 3,09 & 4 & 0,91 \\
MEA01 & 3,19 & 4 & 0,81 \\
MEA02 & 3,34 & 4 & 0,66 \\
MEA03 & 3,34 & 4 & 0,66 \\
\hline
\end{tabular}



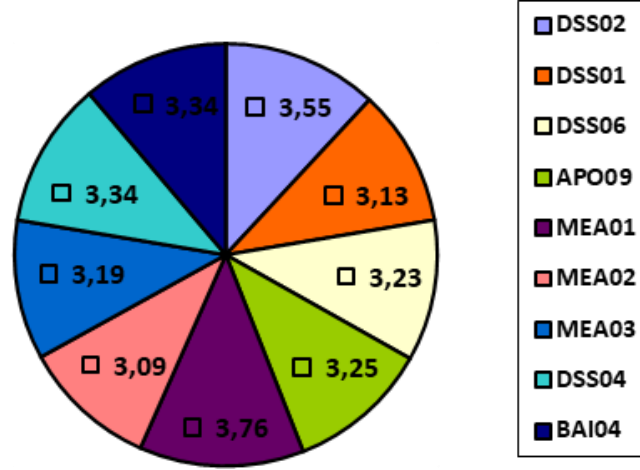

Gambar 2 Grafik hasil Maturity Level

Grafik untuk tingkat kesenjangan / gap dapat dilihat di Gambar 3.

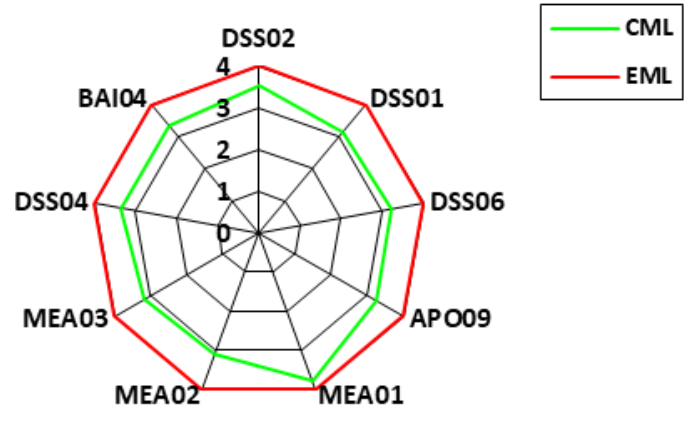

Gambar 3 Grafik Perbandingan Nilai sekarang dan nilai diinginkan

Berlandaskan pada hasil yang sudah diukur dan perhitungan kadar kematangan (maturity leve) pada hasil kuesioner, didapat temuan pada sistem informasi publik Balingtan, yaitu sebagai berikut.

1. Proses APO09 Manage Service Agreements: Dari tahapan perhitungan didapat nilai mean di proses APO09 dengan skor 3,55 yang termasuk pada skala pengukuran kadar kematangan pada level 4 (managed and measurable), dengan artian bahwa manajemen perjanjian layanan sudah diawasi dan teliti serta diukur dengan baik. Pada APO09 ada gap 0,45 dari perbandingan keadaan saat ini dengan harapan manajemen pembiayaan sesuai dengan perjanjian pelayanan. Tujuannya untuk pemeliharaan bertahap peningkatan kualitas layanan TI di Balai Penelitian Lingkungan Pertanian.

2. Proses BAI04 Manage Availability and Capacity: Dari proses perhitungan didapat nilai range di proses BAI04 dengan skor 3,13 dengan artian bahwa pada skala pengukuran kadar kematangan pada level 3 (defined process), dengan artian bahwa pengelolaan ketersediaan dan kapasitas sudah di standarisasi, didokumentasi, dan dikomunikasikan. Pada BAI04 ada gap 0,87 dari perbandingan keadaan sekarang dengan tujuan untuk menjaga kesediaan layanan, pengelolaan sumber daya yang mentok, dan memaksimalkan kualitas kerja sistem dengan prediksi kinerja masa depan dan kebutuhan kapasitas sarana dan prasarana layanan.

3. Proses DSS01 Manage Operations: Dari proses perhitungan didapat nilai range pada proses DSS01 dengan skor 3,23 termasuk pada skala pengukuran kadar kematangan pada level 3 (defined process), yang bermakna bahwa pengelolaan operasi sudah di standarisasi, didokumentasi, dan dikomunikasikan. Pada DSS01 muncul gap 0,77 dari perbandingan keadaan sekarang dengan melakukan ketentuan standar operasi dan kegiatan pengawasan yang diperlukan

4. Proses DSSO2 Manage Service Requests and Incidents: Dari tahapan perhitungan didapatkan nilai range pada tahapan DSS02 dengan skor 3,25 yang termasuk skala pengukuran kadar kematangan pada level 3 (defined process), dengan artian bahwa pengelolaan layanan permintaan dan insiden sudah di standarisasi, didokumentasi, dan dikomunikasikan. Pada DSS02 tampil gap 0,75 dari perbandingan keadaan sekarang dengan tujuan untuk mengklasifikasi, mengutamakan dan merekam insiden dan permintaan yang ada. Manajerial yang dilaksanakan adalah merekam pencatatan permintaan kesesuaian persyaratan layanan dengan jenis layanan dan peristiwa yang ada, lalu merekam informasi secara realitas sehingga bisa diatasi secara tepat.

5. Proses DSS04 Manage Continuity: Dari proses perhitungan didapat nilai range pada tahapan DSS04 dengan skor 3,76 termasuk pada skala pengukuran kesadaran kematangan pada level 4 (managed and measurable), dengan artian bahwa manajerial layanan yang berkelanjutan sudah diukur dan diawasi dengan baik. Pada DSS04 terdapat gap 0,24 dari perbandingan kondisi saat ini dengan tujuan menjaga 
ketersediaan penanganan pengaduan pengguna layanan.

6. Proses DSS06 Manage Business Process Controls: Dari proses perhitungan dapat nilai range pada tahap DSS06 dengan skor 3,09 termasuk pada skala pengukuran tingkat kematangan pada level 3 (defined process), dengan artian bahwa pengelolaan proses bisnis kontrol sudah di standarisasi, didokumentasi, dan dikomunikasikan. Pada DSS06 muncul gap 0,91 dari perbandingan keadaan saat ini dengan tujuan untuk memberikan kepastian bahwa informasi sesuai dengan persyaratan pengendalian informasi yang sebenarnya.

7. Proses MEA01 Monitor, Evaluate and Assess Performance and Conformance: Dari proses perhitungan didapat nilai range pada tahapan MEA01 dengan skor 3,19 termasuk pada skala pengukuran tingkat kematangan pada level 3 (defined process), dengan artian bahwa peninjauan kembali dan penilaian kualitas kerja serta kesesuaian sudah di standarisasi, didokumentasi, dan dikomunikasikan. Pada MEA01 muncul gap 0,81 dari perbandingan keadaan sekarang dengan pengawasan proses kualitas kerja selaras dengan tujuan dan memberikan laporan secara struktural.

8. Proses MEA02 Monitor, Evaluate and Assess the System of Internal Control: Dari proses perhitungan didapat nilai rang pada tahap MEA02 dengan skor 3,34 termasuk pada skala pengukuran tingkat kematangan pada level 3 (defined process), yang bermakna bahwa monitoring, peninjauan kembali, dan penilaian prosedur pengendalian internal sudah sesuai standar, didokumentasi, dan dikomunikasikan. Pada MEA02 muncul gap 0,66 dari perbandingan keadaan sekarang dengan tujuan untuk mengkaji kekurangan kontrol dan efisiensi dalam memulai Tindakan perbaikan layanan.

9. Proses MEA03 Monitor, Evaluate and Assess Compliance With External Requirements: Dari proses perhitungan didapatkan nilai range pada tahapan MEA03 dengan skor 3,34 termasuk pada skala pengukuran tingkat kematangan pada level 3 (defined process), yang berarti bahwa monitoring, pengawasan kembali, dan penilaian kepatuhan dengan persyaratan eksternal sudah di standarisasi, didokumentasi, dan dikomunikasikan. Pada MEA03 muncul gap 0,66 dari perbandingan keadaan sekarang dengan mendapat kepastian bahwa persyaratan sudah dianalisis, dan mengintegrasikan layanan TI dengan kepatuhan petugas dalam pelayanan terkait kesopanan dan keramahan secara keseluruhan.

Usulan yang didapatkan dilakukan penyesuaian dengan penemuan yang ada di lapangan dan disesuaikan dengan hasil kuesioner yang responden isi yang mana meliputi petani, mahasiswa, dosen, peneliti, dan lain-lain.

\section{Kesimpulan}

Proses TI telah dijalankan oleh Balai Penelitian Lingkungan Pertanian (Balingtan) Kementerian Pertanian untuk meraih tujuan bisnis dengan mengamati perencanaan dan adaptasi pada sistem informasi publik
Balingtan untuk membantu peningkatan kualitas kerja lembaga. Adaptasi yang dilaksanakan oleh lembaga sudah pada tahapan jangka lama, dan lembaga menindak bagaimana meraih Tupoksi (Tugas, Pokok, dan Fungsi) dengan lebih terkelola dengan baik. Berlandaskan hasil manajerial TI yang telah dilakukan, menggunakan framework COBIT 5 dapat dijadikan ukuran tingkatan pelayanan dan keandalan sistem informasi publik Balingtan. Kelemahan yang ada pada tiap domain dapat di lihat dari hasil maturity level sehingga dapat diperbaiki untuk menjaga dan meningkatkan penerapan TI pada sistem informasi publik Balingtan.

Dari hasil pembahasan, dapat disimpulkan juga bahwa nilai mean maturity level dari tata kelola TI sistem informasi publik Balingtan adalah sebesar, 3,32 yang diperoleh dari hasil APO09 sebesar 3,55, BAI04 sebesar 3,13, DSS01 sebesar 3,23, DSS02 sebesar 3,25, DSS04 sebesar 3,76, DSS06 sebesar 3,09, MEA01 sebesar 3,19, MEA02 sebesar 3,34, dan MEA03 sebesar 3,34. Jadi, dapat disimpulkan bahwa penerapan TI pada sistem informasi Balingtan ada di level 3 (defined process) dengan artian bahwa sistem informasi sudah di standarisasi, didokumentasi, dan dikomunikasikan dengan baik.

Beberapa saran dan rekomendasi dari hasil penelitian yang ada di antara nya yaitu:

1. Lembaga mengotomatisasi proses-proses yang masih manual dengan digitalisasi.

2. Membuat penataan pengaturan yang dikerjakan oleh staf profesional terhadap manajerial TI di lembaga untuk melaksanakan monitoring dari pekerjaan TI itu sendiri sehingga proses di Balai Penelitian Lingkungan Pertanian (Balingtan) dapat terpantau dengan baik.

3. Dibuat pelatihan terhadap karyawan untuk mengoptimalkan kinerja Sumber Daya Manusia (SDM) di lembaga pemerintahan.

4. Membuat strategi pengelolaan untuk layanan TI agar perkembangan kerja TI pada lembaga bisa dinikmati bagi lembaga pemerintah itu sendiri.

\section{Daftar Pustaka}

[1] C. I. Pramita Ady, P. N. Basuki, and A. D. Manuputty, "Analysis of Information Technology Governance Using the COBIT 5 Framework (Case Study: E-Legal Drafting Legal Section of the Regional Secretariat of Salatiga City)," J. Inf. Syst. Informatics, vol. 1, no. 2, pp. 136-151, 2019.

[2] R. E. Putri, "Penilaian Kapabilitas Proses Tata Kelola TI Berdasarkan Proses DSS01 Pada Framework COBIT 5," J. CoreIT, vol. 2, no. 1, pp. 41-54, 2016.

[3] O. Islamova and R. Volkova, "Effectiveness of internal audit of processes in the organization," 2017, pp. 425-427.

[4] P. Banerjee, P. Banerjee, and S. S. Dhal, "International Journal of Advanced Research in Computer Science and Software Engineering," Int. J., vol. 2, no. 9, pp. 62-70, 2012.

[5] S. Fajarwati, S. Sarmini, and Y. Septiana, "Evaluasi Tata Kelola Teknologi Informasi Menggunakan Kerangka Kerja COBIT 5," JUITA J. Inform., 2018. 
[6] ISACA, A Business Framework for the Governance and Management of Enterprise IT. 2012. [7] Badan Penelitian dan Pengembangan Pertanian, "Rancangan Rencana Strategis Badan Penelitian Dan Pengembangan Pertanian 2020-2024," pp. 0-30, 2019.

[8] S. S. Dwi, "Jurnal Tata Kelola Teknologi Informasi Menggunakan Framework Cobit $5 \mathrm{Pt}$ Santani Agro," J. Tata Kelola Tkenologi Inf. Menggunakan Framew. COBIT 5 PT Santani Agro Persada, p. 8, 2015.

[9] E. Rohaini, Assegaff, and Setiawan, "Evaluasi Tata Kelola Sistem Informasi Menggunakan COBIT 5 pada PT Sinar Sentosa Primatama Jambi," J. Ilm. MEDIA SISFO, 2020.

[10] Irwan, "Evaluasi Pengelolaan Layanan Teknologi Informasi Menggunakan Framework COBIT 5: Studi Kasus Pada Institut Ilmu Sosial Dan Ilmu Politik - IISIP YAPIS BIAK," Gema Kampus IISIP YAPIS Biak, 2017.

[11] A. A. M. Krisna, G. M. A. Sasmita, and G. A. A. Putri, "Perbaikan Tata Kelola Teknologi Informasi pada Lembaga Pemerintah Daerah X," JITTER J. Ilm. Teknol. dan ..., vol. 1, no. 2, 2020.

[12] R. R. Suryono, D. Darwis, and S. I. Gunawan, "Audit Tata Kelola Teknologi Informasi Menggunakan Framework Cobit 5 (Studi Kasus: Balai Besar Perikanan Budidaya Laut Lampung)," J. Teknoinfo, 2018.

[13] M. Maskur, N. Adolong, and R. Mokodongan, "Implementasi Tata Kelola Teknologi Informasi Menggunakan Framework COBIT 5 Di BPMPTSP Bone Bolango," Masy. Telemat. Dan Inf. J. Penelit. Teknol. Inf. dan Komun., 2018.

[14] W. Riyadi, "Analisis Sistem Informasi Akademik dengan Cobit framework,” J. Ilm. Media Sisfo, 2018.

[15] E. Elly and F. Halim, "Evaluasi Tatakelola Infrastruktur Ti Dengan Framework COBIT 5 (Studi Kasus: STMIK-STIE MIKROSKIL)," Sebatik, 2018.
[16] A. Riyandi, A. Sudibyo, B. Wijonarko, M. Rinaldi, and M. F. Fahlevi, "Analisa Audit Sistem Informasi Perpustakaan Menggunakan COBIT FrameWork Library Information System Audit Analysis using COBIT FrameWork," Justin, vol. 08, no. 3, pp. 296-302, 2020.

[17] ISACA, “Cobit 5,” Isaca, 2014.

[18] R. A. Weber, Information Systems Control and Audit, 1st ed. Pearson Education, 1998.

[19] A. Makmur and M. Haming, "Analisis Tata Kelola Teknologi Informasi Pada Terminal Petikemas Makassar Menggunakan Framework Cobit 5," CESJ Cent. Econ. Students ..., vol. 1, no. 1, pp. 56-65, 2018.

[20] R. A. Putri, F. H. Srg, S. Dewi, and T. Yulindra, "Analisis Tata Kelola Sistem Informasi Dengan Framework COBIT-5 : Studi Kasus Pada PT . Batu Karang," vol. 5341, no. April, pp. 35-42, 2020.

[21] L. D. Oktaviana, P. Pribadi, and M. Sabrinawati, "Evaluasi IT Governance Menggunakan Framework COBIT 5 (Studi Kasus : PT . XYZ)," Pro Bisnis, vol. 12, no. 1, pp. 56-68, 2019.

[22] ISACA. and J. W. Lainhart, COBIT 5: A business framework for the governance and management of enterprise IT COBIT 5, vol. 34, no. 1. 2012.

[23] R. G. Mufti and Y. T. Mursityo, "Evaluasi Tata Kelola Sistem Keamanan Teknologi Informasi Menggunakan Framework COBIT 5 Fokus Proses APO13 dan DSS05 ( Studi Pada PT Martina Berto Tbk )," J. Pengemb. Teknol. Inf. dan Ilmu Komput., vol. 1, no. 12, pp. 1622-1631, 2017.

[24] I. D. Lesmono and D. Erca, "Tata Kelola Teknologi Informasi Dengan Metode COBIT 4.1 (Studi Kasus : PT.IMI)," J. Kaji. Ilm., vol. 18, no. 1, 2018. 